\title{
Pomolic acid induces apoptosis in SK-OV-3 human ovarian adenocarcinoma cells through the mitochondrial-mediated intrinsic and death receptor-induced extrinsic pathways
}

\author{
KI HYUN YOO ${ }^{1,2^{*}}$, JONG-HWA PARK ${ }^{1,2^{*}}$, DO KYUNG LEE ${ }^{2}$, \\ YUAN YUAN FU ${ }^{1,2}$, NAM IN BAEK ${ }^{2}$ and IN SIK CHUNG ${ }^{1,2}$ \\ ${ }^{1}$ Department of Genetic Engineering and ${ }^{2}$ Graduate School of Biotechnology, Kyung Hee University, \\ Yongin 446-701, Republic of Korea
}

Received July 25, 2012; Accepted October 17, 2012

DOI: $10.3892 / \mathrm{ol} .2012 .985$

\begin{abstract}
The cytotoxic effect of pomolic acid (PA), a pentacyclic triterpene isolated from flowers of Osmanthus fragrans var. aurantiacus Makino, was investigated in SK-OV-3 human ovarian adenocarcinoma cells. PA dose-dependently inhibited the viability of SK-OV-3 cells. PA-induced apoptosis was further characterized by detection of cell surface annexin $\mathrm{V}$ and sub-G1 apoptotic cell populations. The number of cells immunostained with annexin V-fluorescein isothiocyanate (FITC) increased following treatment with PA. The sub-G1 cell populations also increased in PA-treated SK-OV-3 cells. PA induced the activation of caspase-8, -9 and -3 , critical mediators of apoptosis signaling. PA decreased the mitochondrial transmembrane potential $\left(\Delta \Psi_{\mathrm{m}}\right)$, resulting in the activation of caspase-9. In addition, PA increased the expression of tumor necrosis factor-related apoptosis-inducing ligand (TRAIL)-mediated apoptosis signaling-related death receptor 5 (DR5), mediating caspase-8-involved extrinsic pathway. Taken together, our results indicate that PA induces apoptosis in SK-OV-3 cells, which is mediated by the mitochondrial-mediated intrinsic and death receptor-induced extrinsic pathways.
\end{abstract}

\section{Introduction}

Terpenes are widespread natural compounds involved in various biological activities, playing a significant role in human medicine. They include triterpenes, saponines and

Correspondence to: Dr In Sik Chung, Department of Genetic Engineering and Graduate School of Biotechnology, Kyung Hee University, Yongin 446-701, Republic of Korea

E-mail: ischung@khu.ac.kr

*Contributed equally

Key words: apoptosis, mitochondrial transmembrane potential $\left(\Delta \Psi_{\mathrm{m}}\right)$, death receptor, pomolic acid, SK-OV-3 cells other triterpenoids, representing one of numerous classes of natural compounds. The main groups of triterpenes and saponines are represented by tetracyclic derivatives of protostane, cycloartane, dammarane, euphane and pentacyclic derivatives of ursane, gammacerane, lupane and hopane (1). Pentacyclic triterpenes are secondary metabolites that are based on a 30 -carbon skeleton and synthesized in many plants by the cyclization of squalene (2). These are widely distributed in fruit peel, leaves and stem bark (3). It has been demonstrated that several triterpenes have the ability to induce cancer cell apoptosis and prevent oxidative stress, inflammation and hypertension $(4,5)$.

Pomolic acid (PA) is a pentacyclic triterpene isolated from the flowers of Osmanthus fragrans var. aurantiacus Makino that are found in China, Japan and the southern portion of Korea. The flowers are used by the Chinese to give an aroma to tea or wine and in cosmetics for hair and skin $(6,7)$. Also, dried flowers have neuroprotective, free radical scavenging and anti-oxidative effects (8). PA inhibited the growth of leukemia cell line HL-60 and induced mitochondria-dependent apoptotic cell death (9). PA has been shown to induce apoptosis by activating the caspase cascade through loss of the mitochondrial transmembrane potential $\left(\Delta \Psi_{\mathrm{m}}\right)$, independently of anti-apoptotic Bcl-2 expression in leukemia cells $(9,10)$. PA is suggested to overcome multidrug resistance mediated by overexpression of anti-apoptotic Bcl-2 proteins $(10,11)$. PA also showed anti-proliferative activities against human gastric adenocarcinoma (MK-1), human uterine carcinoma (HeLa) and murine melanoma (B16F10) cells (12). However, the apoptotic mechanisms of PA in human carcinoma cells were not investigated in detail. In our preliminary experiment on cytotoxic effects, PA reduced the viabilities of human ovarian adenocarcinoma SK-OV-3, human colon carcinoma HCT-116, human breast adenocarcinoma MCF-7, SK-BR-3 and human melanoma SK-MEL-5 cells. The greatest inhibition of PA was observed in SK-OV-3 cells (data not shown). To the best of our knowledge, the apoptotic effect of PA on SK-OV-3 cells has not yet been examined. Thus, in this study, we report the PA-induced apoptosis and its molecular mechanism in human ovarian adenocarcinoma SK-OV-3 cells. 


\section{Materials and methods}

Ethical considerations. The study was approved by the Kyung Hee University Institutional Animal Care and Use Committee (Yongin, Korea).

Extraction and isolation of pomolic acid. The dried and powdered flowers (800 g) of Osmanthus fragrans var. aurantiacus Makino, were extracted with $80 \%$ aqueous methanol $(\mathrm{MeOH})$ (3 liters $\mathrm{x} 3$ ). Extracts were partitioned with ethyl acetate (EtOAc; 3 liters $\mathrm{x} 3$ ) and $\mathrm{H}_{2} \mathrm{O}$ (3 liters). The soluble fraction of EtOAc extract ( $30 \mathrm{~g}$ ) was subjected to $\mathrm{SiO}_{2}$ column $(8 \times 15 \mathrm{~cm})$ chromatography (c.c.), eluted with n-hexane-EtOAc $(5: 1 \rightarrow 1: 1,5$ liters of each) and monitored using thin-layer chromatography (TLC) to produce 30 fractions (OSE-1 to OSE-30). Non-soluble precipitate (OSE-P, $2.69 \mathrm{~g}$ ) of EtOAc extracts was applied to the octadecylsilica gel (ODS) c.c. and eluted with $\mathrm{MeOH}-\mathrm{H}_{2} \mathrm{O}$ (4:1, 18 liters) to produce 8 fractions (OSE-P-1 to OSE-P-8). OSE-P-4 [Ve/Vt (elution volume/total volume) $0.27-0.38,224 \mathrm{mg}$ ] was subjected to $\mathrm{SiO}_{2}$ c.c. and eluted with $\mathrm{CHCl}_{3}-\mathrm{MeOH}(25: 1,2.1$ liters) to give 14 fractions (OSE-P-4-1 to OSE-P-4-14). The subfraction OSE-P-4-4 yielded $20 \mathrm{mg} \mathrm{PA}(\mathrm{Ve} / \mathrm{Vt}$ 0.21-0.28, ODS TLC Rf 0.21, $\mathrm{MeOH}-\mathrm{H}_{2} \mathrm{O}=13: 1$ ).

Cell culture. Human ovarian adenocarcinoma SK-OV-3 cells were obtained from the Korea Cell Line Bank (KCLB, Seoul, Korea). Cells were grown at $37^{\circ} \mathrm{C}$ with $5 \% \mathrm{CO}_{2}$ in RPMI-1640 medium with $10 \%(\mathrm{v} / \mathrm{v})$ fetal bovine serum (FBS) and $1 \%(\mathrm{v} / \mathrm{v})$ penicillin-streptomycin. All cell culture media and reagents were purchased from Thermo Scientific Hyclone (Waltham, MA, USA).

Cytotoxic assay. The cytotoxicity of PA was measured using an MTT [3-(4,5-dimethylthiazol-2-yl)-2,5-diphenyltetrazolium bromide, Sigma, St. Louis, MO, USA] colorimetric assay. Cells were seeded onto 96 -well plates at a density of $1 \times 10^{4}$ cells/ well in $100 \mu$ l RPMI-1640 supplemented with 10\% (v/v) FBS. Following $24 \mathrm{~h}$ incubation at $37^{\circ}$, the cells were treated with serum-free RPMI-1640, containing various concentrations of PA. Following a further $24 \mathrm{~h}$ incubation, $50 \mu \mathrm{l}$ MTT [5 mg/ml in phosphate-buffered saline, (PBS)] was added to each well. The cells were incubated at $37^{\circ} \mathrm{C}$ for $2 \mathrm{~h}$. Following removal of the medium, the cells were treated with $100 \mu 1$ dimethyl sulfoxide (DMSO) for $5 \mathrm{~min}$ and then the optical density was measured using a microplate reader (Bio-Tek, Winooski, VT, USA) at $550 \mathrm{~nm}$. Cell viability was calculated as a percentage of viable cells in the PA-treated group $(5,15,25$ and $50 \mu \mathrm{M})$ vs. a control group using the following equation: Cell viability (\%) $=\left[\left(\mathrm{OD}_{\text {Compound }}-\mathrm{OD}_{\text {Blank }}\right) /\left(\mathrm{OD}_{\text {Contol }}-\mathrm{OD}_{\text {Blank }}\right)\right] \times 100$.

Annexin V assay. Modulation of phosphatidylserine externalization during apoptosis was identified using annexin $\mathrm{V}$ conjugated with the fluorescent dye FITC. SK-OV-3 cells were seeded onto 6 -well plates at a density of $3 \times 10^{5}$ cells/ well. Following treatment with $25 \mu \mathrm{M}$ PA for $6 \mathrm{~h}$, the cells were stained with annexin V-FITC conjugate and then imaged under $\mathrm{x} 40$ objective magnification using a confocal laser scanning microscope (LSM 510 Meta, Carl Zeiss, Oberkochen, Germany).
Cell cycle analysis. SK-OV-3 cells were seeded onto 6-well plates at a density of $3 \times 10^{5}$ cells/well. Following dosedependent treatment with PA for various times up to $12 \mathrm{~h}$, cells were collected and washed twice with ice-cold PBS. Cell pellets were fixed in $70 \%$ (v/v) cold ethanol overnight at $-20^{\circ} \mathrm{C}$. Fixed cells were centrifuged, washed and resuspended in $100 \mu \mathrm{l}$ PBS, then mixed with $100 \mu \mathrm{l}$ R Nase A $(1 \mathrm{mg} / \mathrm{ml}$, Sigma) and incubated for $30 \mathrm{~min}$ at $37^{\circ}$. The cells were stained by adding $400 \mu \mathrm{l}$ propidium iodide (PI; $50 \mu \mathrm{g} / \mathrm{ml}$, Sigma). After filtering through a nylon mesh $(40 \mu \mathrm{m})$, the DNA content of stained cells was analyzed using the FACSVantage SE and CellQuest program (BD Biosciences, San Jose, CA, USA).

Mitochondrial membrane potential $\left(\Delta \Psi_{m}\right)$ assay. SK-OV-3 cells treated with $25 \mu \mathrm{M}$ PA for 3 or $6 \mathrm{~h}$ were labeled for $30 \mathrm{~min}$ with $0.1 \mu \mathrm{M}$ tetramethylrhodamine ethyl ester (TMRE; Sigma), a cationic, lipophilic dye that accumulates in the negatively charged mitochondrial matrix and collected by trypsinization. The fluorescence intensity was monitored at $582 \mathrm{~nm}$ (FL2 channel) by FACSVantage SE (BD Biosciences).

Real-time polymerase chain reaction $(P C R)$ analysis. Total RNA was isolated using an RNeasy Mini kit (Qiagen, Hilden, Germany) according to the manufacturer's protocol. DNase I (Takara Bio Inc., Shiga, Japan) -treated total RNA was transcribed into cDNA using an ImProm-II Reverse Transcription System (Promega, Madison, WI, USA). Quantitative real-time PCR was performed using the ABI prism 7000 sequence detection system (Applied Biosystems, Foster City, CA, USA). The reaction was carried out in a total volume of $20 \mu \mathrm{l}$ containing $10 \mu 1$ 2X SYBR Premix EX Taq ${ }^{\mathrm{TM}}$ (Takara Bio Inc.), $1 \mu 1$ each oligonucleotide primer $(10 \mu \mathrm{M})$ and $1 \mu \mathrm{l}$ DNA. The sequences of the sense and antisense primers for death receptor (DR) 5 , DR4 and glyceraldehyde 3-phosphate dehydrogenase (GAPDH) were as follows: DR5 sense: 5'-TGC ACC ACG ACC AGA AAC AC-3'; DR5 antisense: 5'-ATC ACC GAC CTT GAC CAT CC-3'; DR4 sense: 5'-AGG GTC TCA GAG GAG GAG GC-3'; DR4 antisense: 5'-GGA GTC AAA GGG CAC GAT GT-3'; GAPDH sense: 5'-AGG AGG CAT TGC TGA TGA TC-3'; GAPDH antisense: 5'-AGT GAG GGT CTC TCT CTT CC-3'. Following completion of PCR, the data were analyzed using ABI prism 7000 sequence detection system software. The expression of mRNA was normalized with GAPDH.

Western blot analysis. After seeding onto 6-well plates at a density of $3 \times 10^{5}$ cells/well, cells were treated with $25 \mu \mathrm{M}$ PA for various time periods up to $12 \mathrm{~h}$, then lysed with RIPA buffer (Thermo Fisher Scientific Inc., Rockford, IL, USA) supplemented with a protease inhibitor cocktail (Roche, Basel, Switzerland). Protein concentrations were determined using an RC/DC Bio-Rad assay kit (Bio-Rad, Hercules, CA, USA) following the manufacturer's instructions. Protein samples were separated using electrophoresis on $10-15 \%$ polyacrylamide-SDS gel. The electrophoresized proteins on the gel were transferred onto a polyvinylidene fluoride (PVDF) membrane (Pall Life Sciences, Port Washington, NY, USA), blocked with 5\% (w/v) skimmed milk (BD Biosciences), incubated with anti-human cleaved caspase-3 and -8, anti-human caspase-9 (Cell Signaling Technology Inc., Danvers, MA, USA), anti-human DR4 and DR5 (Imgenex, 

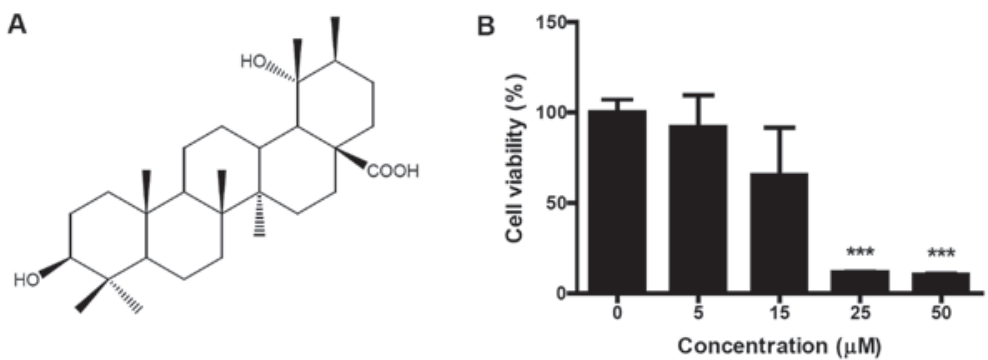

Figure 1. Structure of pomolic acid (PA) and effect of PA on the viability of human ovarian adenocarcinoma SK-OV-3 cells. (A) Structure of PA. (B) PA dosedependently decreased the viability of SK-OV-3 cells. Cells were treated with different concentrations $(0,5,15,25,50 \mu \mathrm{M})$ of PA. Following $24 \mathrm{~h}$ of incubation, cell viability was assessed using an MTT assay. Data are presented as mean \pm standard deviation (SD). ${ }^{* * *} \mathrm{P}<0.001$, between treated and control cells.

A

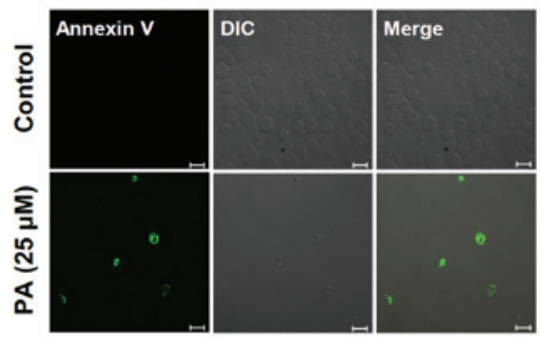

B

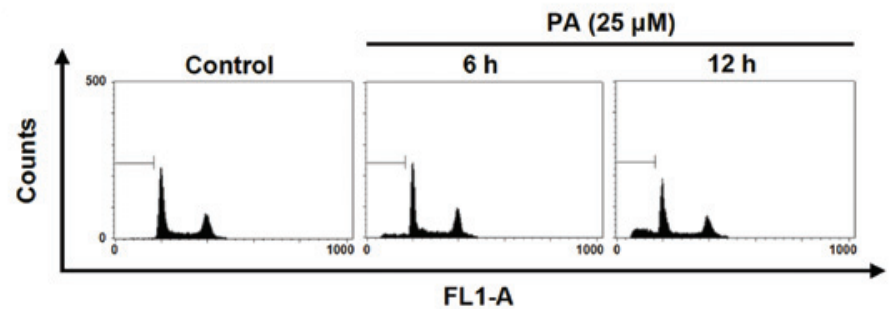

C
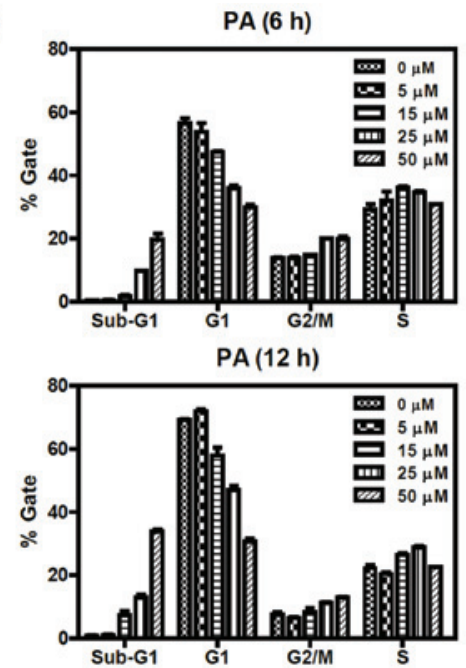

Figure 2. Annexin V and flow cytometric analysis of PA-treated SK-OV-3 cells. (A) PA increased apoptotic cells immunostained with annexin V-FITC. Cells were treated with $25 \mu \mathrm{M}$ PA for $6 \mathrm{~h}$ and stained with annexin V-FITC, then imaged under x40 objective magnification using a confocal microscope (bar=20 $\mu \mathrm{m}$ ). DIC represents the differential interference contrast. (B) PA induced apoptosis in a dose and time-dependent manner. Cells were treated with different concentrations $(0,5,15,25$ and $50 \mu \mathrm{M})$ of PA for $6 \mathrm{~h}$ or $12 \mathrm{~h}$, then sub-G1 populations were measured using a flow cytometer after staining with PI. The sub-G1 populations of cells treated $25 \mu \mathrm{M}$ of PA for $6 \mathrm{~h}$ or $12 \mathrm{~h}$ are represented as a diagram. FL1-A indicates fluorescence 1 area for the measurement of the PI fluorescence intensity (excitation, $488 \mathrm{~nm}$; emission, $530 \mathrm{~nm}$ ). (C) Three independent experiments of (B) were performed and are represented as a bar diagram. PA, pomolic acid; SK-OV-3 cells, human ovarian adenocarcinoma cells; PI, propidium iodide.

San Diego, CA, USA), anti-human PARP and anti-human $\alpha$-tubulin (Santa Cruz Biotechnology, Santa Cruz, CA, USA), then probed with horseradish peroxidase-conjugated antirabbit or mouse IgG antibody (GE Healthcare Life Sciences, Stockholm, Sweden). The membrane was detected using an enhanced chemiluminescent western blotting detection system (GE Healthcare Life Sciences).

Statistical analysis. All data are presented as mean \pm standard deviation (SD). Student's t-test was used to compare different data groups. $\mathrm{P}<0.05, \mathrm{P}<0.01$ and $\mathrm{P}<0.001$ were considered to indicate statistically significant differences.

\section{Results}

PA demonstrates dose-dependent cytotoxic effects. PA was isolated from flowers of Osmanthus fragrans var. aurantiacus Makino (Fig. 1A). Identification of the structure was confirmed on the basis of several spectroscopic analyses, including infrared (IR), ${ }^{1} \mathrm{H}$ - and ${ }^{13} \mathrm{C}$-nuclear magnetic resonance (NMR) and 2D-NMR (correlation spectroscopy, COSY; heteronuclear single quantum coherence, HSQC and heteronuclear multiplebond correlation spectroscopy, HMBC) (data not shown). To evaluate the cytotoxic effect of PA on SK-OV-3 cells, cells were treated with different concentrations $(5,15,25$ and $50 \mu \mathrm{M}$ ) of PA for $24 \mathrm{~h}$ and cell viabilities were measured using an MTT assay. PA dose-dependently inhibited the viability of SK-OV-3 cells (Fig. 1B). When $50 \mu \mathrm{M}$ PA was treated for $24 \mathrm{~h}$, the viability of SK-OV-3 cells decreased to $10.3 \%$ of that for untreated control cells. $\mathrm{IC}_{50}(50 \%$ inhibitory concentration) value occurred between 15 and $25 \mu \mathrm{M}$.

$P A$ induces apoptosis in SK-OV-3 cells. To determine whether the cytotoxic effect of PA was caused by apoptosis, PA-treated SK-OV-3 cells were immunostained with annexin V-FITC conjugate and monitored under a confocal microscope (Fig. 2A). Annexin V-FITC-stained cells were observed in PA-treated cells, but not in an untreated control group. Cell cycle analysis was performed to determine the sub-G1 apoptotic population of PA-treated SK-OV-3 cells. Cells were treated with different concentrations $(5,15,25$ and $50 \mu \mathrm{M})$ of PA for 6 or $12 \mathrm{~h}$ and their DNA contents were analyzed using flow cytometry 
A

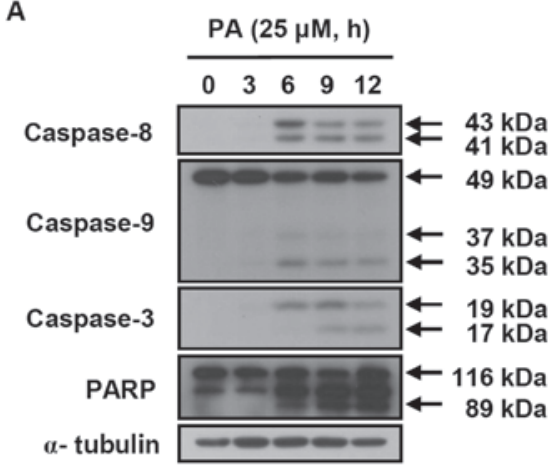

C

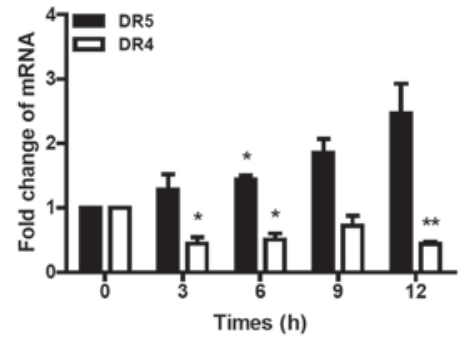

B

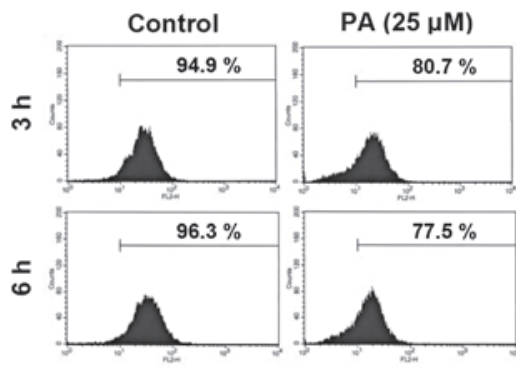

D

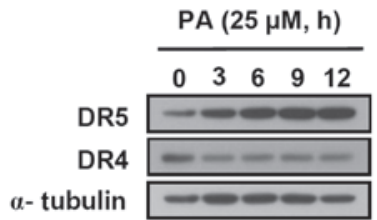

Figure 3. Effect of PA on caspase activation cascade and TRAIL signaling-related death receptors DR4 and DR5. (A and D) Protein extracts were prepared from $25 \mu \mathrm{M}$ PA-treated cells. The cleavage of caspase- $8,-3,-9$ and PARP (A) and the amounts of DR4 and DR5 proteins (D) were determined using western blot analysis. $\alpha$-tubulin was used as a control. (B) Cells were treated with $25 \mu \mathrm{M}$ PA for the indicated times. Flow cytometry was performed to determine the loss of mitochondrial transmembrane potential $\left(\Delta \Psi_{\mathrm{m}}\right)$. The percentages of cells showing fluorescence intensities up to 10 are represented in the diagram. (C) Real-time PCR was performed to determine the transcript levels of DR5 and DR4. The expression of the mRNA was normalized with GAPDH. Data are presented as mean \pm standard deviation $(\mathrm{SD}) .{ }^{*} \mathrm{P}<0.05$ and ${ }^{* *} \mathrm{P}<0.01$ were considered to indicate statistically significant differences between treatment and control groups. PA, pomolic acid; TRAIL, tumor necrosis factor-related apoptosis-inducing ligand; PARP, poly ADP ribose polymerase; PCR, polymerase chain reaction; GAPDH, glyceraldehyde 3-phosphate dehydrogenase.

following propidium iodide (PI) staining. As shown in Fig. 2B and $\mathrm{C}$, the number of cells in the sub-G1 population increased in a time- and dose-dependent manner. Following $6 \mathrm{~h}$ incubation with $5,15,25$ and $50 \mu \mathrm{M}$ PA, the sub-G1 populations increased to $0.6,1.8,9.8$ and $19.8 \%$, respectively. The sub-G1 populations of cells treated with $5,15,25$ and $50 \mu \mathrm{M}$ PA for $12 \mathrm{~h}$ increased to $1.01,7.41,13.01$ and $33.93 \%$, respectively. Taken together, these results indicate that PA induces apoptosis in SK-OV-3 cells.

$P A$ induces the activation of the caspase cascade. The activation of the caspase cascade was determined in SK-OV-3 cells treated with $25 \mu \mathrm{M}$ PA for indicated times (3, 6, 9 and $12 \mathrm{~h}$ ). Cleaved caspase- 8 (41 and $43 \mathrm{kDa}$ ) and caspase-3 (17 and $19 \mathrm{kDa}$ ) were increased by the treatment of PA (Fig. 3A). PA induced the reduction of procaspase- $9(49 \mathrm{kDa})$ and increased the cleaved caspase-9 (35 and $37 \mathrm{kDa}$ ). PA also induced the cleavage of poly ADP-ribose polymerase (PARP). These results indicate that $\mathrm{PA}$ induces apoptosis in SK-OV-3 cells via the activation of the caspase cascade.

$P A$ reduces the mitochondrial transmembrane potential $\left(\Delta \Psi_{m}\right)$ and increased the expression of DR5 in SK-OV-3 cells. To determine the effect of PA on mitochondrial transmembrane potential $\left(\Delta \Psi_{\mathrm{m}}\right)$, SK-OV-3 cells were treated with $25 \mu \mathrm{M}$ PA for 3 or $6 \mathrm{~h}$ and labeled with TMRE. The fluorescence intensity was measured using flow cytometry. The number of TMREstained cells showing fluorescence intensities up to 10 were 80.7 and $77.5 \%$ following 3 and $6 \mathrm{~h}$ incubation of $25 \mu \mathrm{M}$ PA, respectively (Fig. 3B). This means that the treatment of $25 \mu \mathrm{M}$
PA for 3 and $6 \mathrm{~h}$ reduced the $\Delta \Psi_{\mathrm{m}}$ by 15 and $19.5 \%$, respectively, compared to PA-nontreated cells. This indicates that PA induces the loss of mitochondrial transmembrane potential, resulting in the activation of caspase-9.

To investigate the effect of PA on death receptor-induced extrinsic apoptosis pathway, the expression levels of DR4 and DR5 were analyzed using real-time PCR and western blot analysis. As shown in Fig. 3C, DR5 transcript was timedependently increased in PA-treated SK-OV-3 cells, resulting in 1.3, 1.7, 2.3 and 2.5-fold increases following 3, 6, 9 and $12 \mathrm{~h}$ incubation with $25 \mu \mathrm{M}$ PA, respectively. The protein levels of DR5, based on densitometry (Fig. 3D), increased 3.5, 5.1, 6 and 6.1-fold, respectively, following 3,6,9 and $12 \mathrm{~h}$ incubation with $25 \mu \mathrm{M}$ PA. However, DR4 transcript and protein levels decreased in PA-treated SK-OV-3 cells. This indicates that PA increases expression of DR5, resulting in the activation of caspase-8, a caspase cascade mediator of the death receptorinduced extrinsic apoptosis pathway.

\section{Discussion}

PA inhibited the growth of leukemia HL-60 cells (9) and showed anti-proliferative activities in several human carcinoma cells including human gastric adenocarcinoma (MK-1), human uterine carcinoma (HeLa) and murine melanoma (B16F10) cells (12). Although mitochondria-dependent apoptotic cell death was evaluated in leukemia HL-60 cells, PA-induced apoptotic mechanisms of human carcinoma cells were not investigated in detail. In a preliminary experiment, we deter- 
mined the cytotoxic effect of PA on the viabilities of human carcinoma cells. The greatest inhibition of PA was observed in SK-OV-3 cells (data not shown). We chose SK-OV-3 cells to investigate PA-induced apoptotic mechanisms of human carcinoma cells. In this study, we examined the effect of PA on the viability of human ovarian adenocarcinoma SK-OV-3 cells and investigated the mechanisms involved in PA-induced apoptosis. PA dose-dependently inhibited the viability of SK-OV-3 cells (Fig. 1B) and induced apoptosis, which was characterized by detection of cell surface annexin $\mathrm{V}$ and sub-G1 apoptotic cell populations (Fig. 2).

The caspase- 3 activation cascade played a central role in apoptotic mechanisms (13) as determined in PA-treated SK-OV-3 cells. Cleaved caspase- $8,-9$ and -3 levels increased following treatment with PA (Fig. 3A). Our findings indicate that PA activates two major apoptotic pathways, intrinsic and extrinsic, as is the case for other reported triterpenoids, to induce apoptosis through mitochondria-mediated intrinsic and death receptor-induced extrinsic pathways $(14,15)$. PA has been reported to induce apoptosis by activation of caspase- 9 and -3 through the loss of mitochondrial transmembrane potential $\left(\Delta \Psi_{\mathrm{m}}\right)$ in leukemia cells (9). In SK-OV-3 cells, PA was also found to reduce the mitochondrial transmembrane potential $\left(\Delta \Psi_{\mathrm{m}}\right)$ (Fig. 3B). This implies that PA induces apoptosis in SK-OV-3 cells via a mitochondria-mediated intrinsic pathway.

In addition, PA induced activation of caspase- 8 , a caspase cascade mediator of the death receptor-induced extrinsic pathway. This indicates that PA induces apoptosis through the death receptor-induced extrinsic pathway. Recently, triterpenoids such as celastrol and ursolic acid have been suggested to potentiate tumor necrosis factor-related apoptosis-inducing ligand (TRAIL)-induced apoptosis through upregulation of DR4 and/or DR5 $(16,17)$. In our previous study, 3-O-acetyloleanolic acid was also shown to induce apoptosis in HCT-116 cells, which is mediated by upregulation of DR5 (18). TRAIL is a TNF family member showing anti-tumor activity in various cancer cell types as well as minimal cytotoxicity to normal cells and tissues (19). The binding between TRAIL and the two death receptors DR4 (TRAILR1/APO-2) and DR5 (TRAILR2/KILLER) leads to oligomerization of the death receptors and activation of the death receptor-induced extrinsic pathway (20). DR5 and DR4 signaling induces apoptosis via caspase-8-mediated activation of the caspase cascade $(21,22)$. PA increased the expression of DR5, increasing induction of the caspase-8-mediated extrinsic pathway. To the best of our knowledge, this is the first report showing that PA induces apoptosis in SK-OV-3 cells as well as upregulation of TRAIL signaling-related DR5 in PA-mediated apoptosis.

In conclusion, our results demonstrated for the first time PA-induced apoptotic mechanisms in human ovarian adenocarcinoma SK-OV-3 cells. Our findings suggest that PA increases expression of TRAIL signaling-related death receptor DR5 and induces apoptosis in SK-OV-3 cells via the mitochondria-mediated intrinsic and the death receptorinduced extrinsic pathway.

\section{Acknowledgements}

This study was supported by grants from the Basic Science Research Program through the National Research Foundation of Korea (NRF) funded by the Ministry of Education, Science and Technology (2012001575) and from Kyung Hee University in 2010 (KHU-20110257).

\section{References}

1. Patocka J: Biologically active pentacyclic triterpenes and their current medicine signification. J Appl Biomed 1: 7-12, 2003.

2. Phillips DR, Rasbery JM, Bartel B and Matsuda SP: Biosynthetic diversity in plant triterpene cyclization. Curr Opin Plant Biol 9: 305-314, 2006.

3. Jager S, Trojan H, Kopp T, Laszczyk MN and Scheffler A: Pentacyclic triterpene distribution in various plants - rich sources for a new group of multi-potent plant extracts. Molecules 14: 2016-2031, 2009

4. Baek JH, Lee YS, Kang CM, Kim JA, Kwon KS, Son HC and Kim KW: Intracellular $\mathrm{Ca}^{2+}$ release mediates ursolic acidinduced apoptosis in human leukemic HL-60 cells. Int J Cancer 73: 725-728, 1997.

5. Yamaguchi Y, Yamada K, Yoshikawa N, Nakamura K, Haginaka $\mathbf{J}$ and Kunitomo M: Corosolic acid prevents oxidative stress, inflammation and hypertension in SHR/NDmcr-cp rats, a model of metabolic syndrome. Life Sci 79: 2474-2479, 2006.

6. Duke JA and Ayensu ES: Medicinal Plants of China. Vol 2. Reference Publications Inc., Algonac, MI, USA, pp381, 1985.

7. Hedrick UP: Sturtevant's Edible Plants of the World. Dover Publications, Mineola, NY, USA, pp686, 1972.

8. Lee HH, Lin CT and Yang LL: Neuroprotection and free radical scavenging effects of Osmanthus fragrans. J Biomed Sci 14: 819-827, 2007.

9. Fernandes J, Weinlich R, Castilho RO, Kaplan MAC, Amarante-Mendes GP and Gattass CR: Pomolic acid triggers mitochondria dependent apoptotic cell death in leukemia cell line. Cancer Lett 219: 49-55, 2005.

10. Fernandes J, Weinlich R, Castilho RO, Amarante-Mendes P and Gattass CR: Pomolic acid may overcome multidrug resistance mediated by overexpression of anti-apoptotic Bcl-2 proteins. Cancer Lett 245: 315-320, 2007.

11. Vasconcelos FC, Gattass RR, Rumjanek VM and Maia RC: Pomolic acid-induced apoptosis in cells from patients with chronic myeloid leukemia exhibiting different drug resistance profile. Invest. New Drugs 25: 525-533, 2007.

12. Yoshida M, Fuchigami M, Nagao TT, et al: Antiproliferative constituents from umbelliferase plants VII. Active triterpenes and rosmarinic acid from Centella asiatica. Biol Pharm Bull 28: $173-175,2005$.

13. Zheng TS, Schlosser SF, Dao T, Hingorani R, Crispe IN, Boyer JL and Flavell RA: Caspase-3 controls both cytoplasmic and nuclear events associated with Fas-mediated apoptosis in vivo. Proc Natl Acad Sci USA 95: 13618-13623, 1998.

14. Hengartner MO: The biochemistry of apoptosis. Nature 407: 770-776, 2000

15. Lee B, Lee DY, Yoo KH, Baek NI, Park JH and Chung IS: Calenduloside E 6'-methyl ester induces apoptosis in CT-26 mouse colon carcinoma cells and inhibits tumor growth in a CT-26 xenograft animal model. Oncol Lett 4: 22-28, 2012.

16. Sung B, Park B, Yadav VR and Aggarwal BB: Celastrol, a triterpene, enhances TRAIL-induced apoptosis through the down-regulation of cell survival proteins and up-regulation of death receptors. J Biol Chem 285: 11498-11507, 2010.

17. Prasad S, Yadav VR, Kannappan R and Aggarwal BB: Ursolic acid, a pentacyclin triterpene, potentiates TRAIL-induced apoptosis through p53-independnet up-regulation of death receptors. J Biol Chem 286: 5546-5557, 2011.

18. Yoo KH, Park JH, Cui EJ, et al: 3-O-Acetyloleanolic acid induces apoptosis in human colon carcinoma HCT-116 cells. Phytother Res doi: 10.1002/ptr.4616, 2012.

19. Pitti RM, Marsters SA, Ruppert S, Donahue CJ, Moore A and Ashkenazi A: Induction of apoptosis by Apo-2 ligand, a new member of the tumor necrosis factor cytokine family. J Biol Chem 271: 12687-12690, 1996.

20. Zhang Land Fang B: Mechanisms of resistance to TRAIL-induced apoptosis in cancer. Cancer Gene Therapy 12: 228-237, 2005

21. Ashkenazi A and Dixit VM: Death receptors: Signaling and modulation. Science 281: 1305-1308, 1998.

22. Wajant H, Gerspach J and Pfizenmaier K: Tumor therapeutics by design: targeting and activation of death receptors. Cytokine Growth Factor Rev 16: 55-76, 2005. 